\title{
A content analysis of e-cigarettes selling propositions on South African retail websites
}

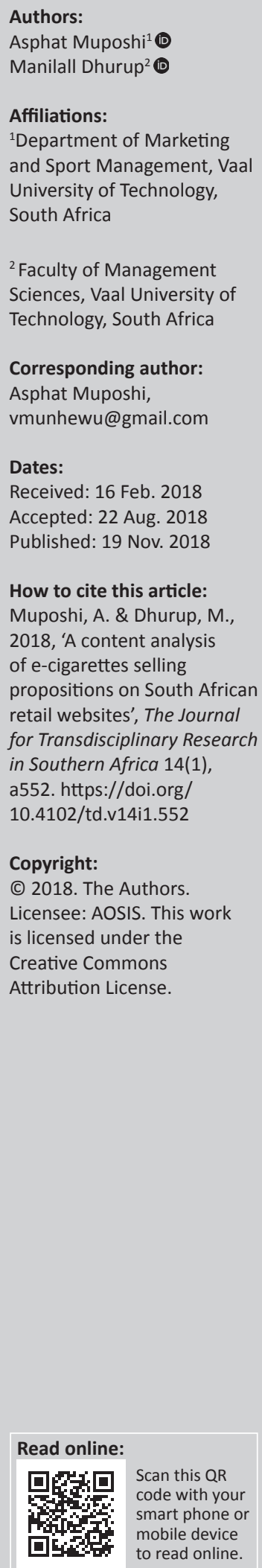

Electronic cigarettes remain unregulated in South Africa, yet their marketing and sale is proliferating on online platforms such as websites. Until now, little was known regarding the nature of selling propositions used on such platforms. Against this background, this study provides the findings of a content analysis of 17 websites dedicated to the marketing and selling of electronic cigarettes in South Africa. With the aid of a website search research methodology, a detailed search and analysis of websites marketing electronic cigarettes in South Africa was performed from July to October 2017. The study identified smoking cessation, environmental friendliness, healthiness, cost-effectiveness, hedonic value, convenience and safety as the main selling propositions used to market electronic cigarettes in South Africa. The study provides important insights to consumers who intend to use electronic cigarettes and policymakers who intend to monitor and regulate the consumption of electronic cigarettes in South Africa.

\section{Introduction and background to the study}

Globally, the consumption of tobacco cigarettes is associated with high levels of morbidity and mortality (Kaisar et al. 2016). For this reason, for decades, the public health fraternity has grappled with the search for a safe alternative to tobacco cigarettes (Hajek et al. 2014). As part of efforts to address this challenge, in 2003, Hon Lik, a Chinese pharmacist, invented the electronic cigarette (Kaisar et al. 2016). The electronic cigarette, which was subsequently patented as Electronic Atomisation Cigarette (US20070267031A1) in 2007, was introduced in the market as a potential substitute to tobacco cigarettes (Kaisar et al. 2016). In the marketplace, e-cigarettes are positioned as nicotine reduction therapies as well as smoking cessation aids (Dinakar \& O'Connor 2016; Wasowicz, Feleszko \& Goniewicz 2015). The global market of e-cigarettes has grown tremendously since their commercialisation. Goldsmith (2016) estimates that by 2021 the global e-cigarette market will be worth $\$ 32$ billion.

\section{Characterisation of e-cigarettes}

Electronic cigarettes, hereafter referred to as e-cigarettes, are defined as battery-enabled devices that allow users to inhale nicotine in vaporised form (Pisinger \& Dossing 2014). E-cigarettes are consumed by inhaling a vapour which is formed from a heated flavoured electronic liquid (Pokhrel et al. 2015). The act of inhaling the e-cigarette vapour is referred to as 'vaping' and users of e-cigarettes are commonly known as 'vapers' (Pokhrel et al. 2015). The prime target market for e-cigarettes include users of conventional cigarettes who intent to quit and those who want a safer alternative to tobacco cigarettes (Dinakar \& O'Connor 2016). E-cigarettes have evolved significantly since their market entry. There are three distinct cohorts of e-cigarettes in the marketplace. The first generation of e-cigarettes was designed in a manner that resembles conventional tobacco cigarettes (Clarke \& Lusher 2017). This design was done to promote ease of identification and speed up adoption rate (McQueen, Tower \& Sumner 2011). The second-generation e-cigarettes are aesthetically improved and have a distinct design (Clarke \& Lusher 2017). They are also accompanied by a wide array of flavours coupled with variations in nicotine strength (Dawkins et al. 2013). The third-generation of e-cigarettes, also known as modified e-cigarettes, are customised to suit user requirements and they also include a wide range of flavours such as vanilla, chocolate, fruit and mint-menthol amongst others (Clarke \& Lusher 2017; West \& Brown 2014). The utility of second- and third-generation e-cigarettes stems from the ability of users to alter the voltage of batteries to either increase or decrease nicotine levels and the thickness of vapour inhaled (Clarke \& Lusher 2017).

E-cigarettes in their various forms have been characterised as controversial products (Dinakar \& O'Connor 2016). The public health fraternity is deeply worried about the claims used to market 
e-cigarettes (Kim \& Shin 2013). This is because the long-term health effects of e-cigarettes are not known (West \& Brown 2014). There is also a growing concern that e-cigarettes may entice young consumers to initiate using other tobacco products (Grana 2013). In most instances, electronic cigarettes are being used to circumvent conventional tobacco controls (Paek et al. 2014). As a result of the foregoing concerns, countries such as Canada, Brazil, Uruguay, Norway and Seychelles have banned the marketing and use of e-cigarettes (Fox 2013). In spite of the controversy associated with e-cigarettes, they are growing in popularity aided by a surge in retail websites. For example, www.e-cigarette-forum.com, commonly known as the e-cigarette forum, is one of the biggest global e-cigarette retail websites.

\section{Contextual setting of the study}

Consistent with the global trend, the use of e-cigarettes is also escalating in South Africa (Van Rensburg \& Moodley 2017). The growth in demand of e-cigarettes has resulted in the formation of advocacy bodies such as the Electronic Cigarettes Association in South Africa and Vapour Product Association. E-cigarettes are still not regulated under the Tobacco Products Control Act of 1993 (Visagie 2017). Although the Amended Medicines and Related Substances Act of 1965 directs e-cigarettes to be registered with the Medicines Control Council for lawful sale, Visagie (2017) notes that e-cigarettes are currently promoted as consumer products and thus fall away from the ambit of tobacco laws. Additionally, mixed views are prevalent amongst public health regulators, researchers and e-cigarettes marketers regarding the health benefits of e-cigarettes (Van Rensburg \& Moodley 2017). Moreover, there is also lack of consensus on how to define and characterise e-cigarettes (Caruana 2016). In the midst of these contestations, there is a significant increase in the number of websites marketing e-cigarettes in South Africa. As of 2016, Caruana (2016) reports that an estimated 70 franchises were marketing e-cigarettes in South Africa, mostly using online platforms. This study therefore provides a content analysis of selling propositions used to market e-cigarettes on South African websites.

\section{Problem statement}

In spite of rapid adoption and use, e-cigarettes continue to generate much debate. This debate, amongst health practitioners, researchers and the smoking public, is stirred by the existence of mixed views related to the safety and health benefits of e-cigarettes (Dufort \& Owila 2014; Muposhi \& Dhurup 2016; Pardun, McKeever \& Bedingfield 2017). In particular, the public health fraternity across the globe is deeply worried about unsubstantiated health claims used to market e-cigarettes, more so on online platforms (Kim \& Shin 2013; Zhu et al. 2014). Proponents of e-cigarettes on the other hand herald them as novel products that have radically changed the smoking experience, with the ability to assist smokers to quit use of tobacco cigarettes (Barbeau, Burda \& Siegel 2013).
Of paramount concern to public health practitioners is the proliferation of unregulated online platforms that promote and sell e-cigarettes (Zhu et al. 2014). Additionally, there is a growing concern that such online platforms may entice young consumers to initiate using e-cigarettes (Paek et al. 2014). Whilst studies have been conducted in other jurisdictions to assess the marketing claims used to market e-cigarettes on online platforms (e.g. Grana \& Lingh 2014; Paek et al. 2014), there is no known South African study that has sought to provide content analysis of online e-cigarettes marketing claims. Such a study is considered to be of critical importance because, as noted by Paek et al. (2014), information conveyed on online platforms is influential in shaping the perceptions and attitudes of prospective and regular users of e-cigarettes. As the popularity of e-cigarettes on online platforms grows, Zhu et al. (2014) emphasised the importance of monitoring the nature of marketing messages used to market them. Against this background, the research question that directed this study was: What are the selling propositions used to promote e-cigarettes on South African retail websites?

\section{Research methodology Research method, target population and sampling}

The study was underpinned by the constructivism research paradigm because the primary objective was to analyse and interpret the selling propositions used to market e-cigarettes on South Africa websites. The study employed a web search research methodology. The target population was purposively sampled from a 70-member listing of the Electronic Cigarettes Association in South Africa. Consistent with the tenets of purposive sampling, a website inclusion criterion was established as follows: (1) website should be in English language, (2) only active websites were selected and (3) the website needed to be registered in South Africa and dedicated to the marketing of e-cigarettes. Franchise websites selling e-cigarettes not registered in South Africa were excluded from the study. Other online platforms used to market e-cigarettes were not considered in this study. Seventeen websites met the inclusion criterion and were considered for analysis.

\section{Data collection}

Document analysis was utilised to collect data in this study. Prior to data collection, the search question was defined as recommended by Best et al. (2014). The data collection protocol involved the collection of data independently by two researchers from July to October 2017 by browsing, clicking and transcribing the marketing claims used on e-cigarette retail websites pages. Data were also collected from hyperlinks, videos and adverts that were used to provide detailed information to users of e-cigarettes. To address the challenge associated with instability of data collected on websites because of regular updates, researchers followed the advice of Jansen and Pooch (2001) 
who suggested the need to collect data for a clearly defined period. In this study, data were collected for a period of 4 months and during that period no major updates were noted on surveyed websites that affected the integrity of the data collected. A two-stage process was followed with the objective of noting the changes in value propositions used to sell e-cigarettes on identified websites. The first search and analysis was conducted in July 2017 followed by the second search and analysis in October 2017. The search period of 4 months provided reasonably longitudinal data set that have the potential to capture the majority of selling propositions used to market e-cigarettes on websites in South Africa.

\section{Data analysis}

In accordance with constructivist tenets, the method of data analysis followed in this study involved a content analysis of websites' text. Websites' content was analysed by following a three-stage approach recommended by Corbin and Strauss (1990) which involves open coding, axial coding and integration. There was consensus by the two researchers on the themes that emerged from the content that was gleaned and analysed from South African e-cigarettes retail websites. Representative excerpts and themes that emanated from content analyses of e-cigarettes retail websites in South Africa are summarised in Table 1.

\section{Discussion of results}

The themes that emerged from content analysis are discussed as follows.

\section{Healthiness}

Health benefit is one of the most frequently used value propositions on e-cigarettes retail websites in South Africa. This is despite the fact that there is no conclusive scientific evidence that confirms that e-cigarettes are healthier than conventional cigarettes (Dufort \& Owila 2014; Etter \& Bullen 2011; Kaisar et al. 2016). Although e-cigarettes are positioned as low in nicotine, Hajek et al. (2014) note that, in practice, the uptake of nicotine tends to increase with increased vaping behaviour and the type of e-liquids used. This view holds in the case of third-generation e-cigarettes which are associated with high levels of nicotine (Etter \& Bullen 2011). Although there is an option to reduce the nicotine concentration by diluting, McQueen et al. (2011) note that not all consumers of e-cigarettes make an effort to do so. Apart from nicotine, the flavours used to manufacture e-liquids such as glycerine and propylene glycol are known to have side effects. For example, Grana, Benowitz and Glantz (2014) report that continuous exposure to propylene glycol potentially results in respiratory irritation and its inhalation is associated with nervous system-related ailments. Given the adverse health effects of e-cigarettes, Dufort and Owila (2014) contend that the use of health claims to market e-cigarettes is misleading and should be discouraged.
TABLE 1: Content analysis of e-cigarettes retail websites.

\begin{tabular}{|c|c|}
\hline Theme & Websites excerpts \\
\hline Healthiness & $\begin{array}{l}\text { 'It's the safer alternative without the harmful effects of } \\
\text { burning tobacco, smoke, tar and carbon monoxide. Tobacco } \\
\text { cigarettes are all about nicotine, tar and carbon monoxide } \\
\text { which increase the risk of cancer, strokes and heart } \\
\text { disease...'- - https://twispcue.co.za/why-vape/ } \\
\text { 'Vaporisers can give you all the things you need: The capacity } \\
\text { to have control nicotine levels, zero ash, zero tar, no impact } \\
\text { on your teeth colour, no bad taste in your mouth' - http:// } \\
\text { www.vapersa.co.za/ }\end{array}$ \\
\hline $\begin{array}{l}\text { Smoking cessation } \\
\text { aid }\end{array}$ & $\begin{array}{l}\text { 'Are you looking for something a little trendy to smoke; } \\
\text { perhaps you would like to support the environment with our } \\
\text { smokeless e-cigs range or maybe you are thinking of kicking } \\
\text { the habit altogether...' - https://www.twisp.co.za/ecigs }\end{array}$ \\
\hline Convenience & $\begin{array}{l}\text { 'Our e-cigarettes provide ultimate functionality and our } \\
\text { flavours have been specially developed to enhance your } \\
\text { experience. Simply charge, refill and enjoy. You can smoke } \\
\text { indoors and everywhere including tobacco free zones...' } \\
\text { 'You won't be the party pooper breathing and blowing smoke } \\
\text { in the faces of non-smokers. You will smell good even after } \\
\text { enjoying that perfect puff. Check out the Trending Twisper' - } \\
\text { https://www.twisp.co.za/ecigs }\end{array}$ \\
\hline Cost-effectiveness & $\begin{array}{l}\text { 'Our cheaper starter kit gives you a head start which includes } \\
\text { free delivery. You may save money if you participate in our } \\
\text { online promotions such as contests, give away, raffles as well } \\
\text { as online news, we offer quality e-cigarettes at an affordable } \\
\text { price, accommodating tighter budgets' https://www.easypuff. } \\
\text { co.za/ } \\
\text { 'If you are a smoker, simply cannot bear the thought of giving } \\
\text { up your daily "comfort" but are finding cigarettes are } \\
\text { becoming way too expensive, our starter pack comes with the } \\
\text { whole enchilada - single device, charger, spare atomiser coil } \\
\text { and } 5 \text { ml of tobacco which will enable you to not only save on } \\
\text { costs, but will ensure you can start "Twisping" the night } \\
\text { away' - https://www.twisp.co.za/ecigs }\end{array}$ \\
\hline Hedonic value & $\begin{array}{l}\text { 'Perhaps you are tired of being told you taste like an ashtray } \\
\text { when you lock lips with the love of your life or are often } \\
\text { found crouching in dark corners catching a little puff that } \\
\text { you are not prepared to give up for anything in the world? } \\
\text { Say goodbye to smoking around the corner, on balconies or } \\
\text { in the dark alleys around restaurants that don't permit } \\
\text { smoking' - https://www.vapeking.co.za/promotions.html } \\
\text { 'Are you keen to go the e-cigarette route smoking e-vapours } \\
\text { that will leave you pleasantly satisfied? You too, can enjoy a } \\
\text { clean, odourless smoking sensation...' - http://www.vapersa. } \\
\text { co.za/ } \\
\text { 'They are purely a recreational alternative to smoking normal } \\
\text { cigarettes and used purely for pleasure. It can still look and } \\
\text { feel like you are smoking, without any smell of burning paper } \\
\text { and tobacco to worry about. The vapour disintegrates into the } \\
\text { atmosphere, so bystanders are safe from any poisonous } \\
\text { smoke' - http://electronic-cigarette-suppliers.co.za/ } \\
\text { 'Many people are making the switch to vaporizers over } \\
\text { analogue cigarettes and for many reasons: It's more } \\
\text { affordable, there are more options, it is more widely } \\
\text { accepted, and it can easily become a modern hobby' - } \\
\text { https://www.e-cig-brands.com/e-cigarette/the-best-e-cigs- } \\
\text { vaporizers-of-south-africa/ }\end{array}$ \\
\hline $\begin{array}{l}\text { Environmental } \\
\text { friendliness }\end{array}$ & $\begin{array}{l}\text { 'if you want to be cool and classy, environmentally friendly } \\
\text { and smokeless but would still love a puff or two, our E-Cigs } \\
\text { will offer you the perfect opportunity to continue in the vein } \\
\text { you have been accustomed to - all this but without the } \\
\text { smoke' - https://www.twisp.co.za/ecigs }\end{array}$ \\
\hline Safety & $\begin{array}{l}\text { 'The electronic cigarette produces a smoke-like vapour } \\
\text { without burning tobacco. This means NO second-hand } \\
\text { smoke will harm others around you because electronic } \\
\text { cigarettes contain NO carcinogens or tar. You will be able } \\
\text { to enjoy smoking (vaping) in public places with complete } \\
\text { confidence' - https://www.easypuff.co.za/. }\end{array}$ \\
\hline
\end{tabular}

\section{Smoking cessation aid}

On retail websites, e-cigarettes are also positioned as aids that assist users to quit smoking conventional cigarettes. Additionally, such quitting claims are accompanied by testimonials of users of e-cigarettes who have successfully quit smoking tobacco cigarettes. In spite of the prevalence of this proposition on e-cigarette retail websites, Grana et al. (2014) note that empirical evidence supporting this view is limited. Contrary to the quitting aid proposition, longitudinal studies conducted by Chen (2013) as well as Etter and Bullen (2014) refute the claim that e-cigarettes are effective as smoking cessation aids. In fact, emerging evidence suggests that users of e-cigarettes are stopping using them as a result 
of respiratory problems, headaches, poor quality and throat ailments (Etter \& Bullen 2011). Owing to the lack of conclusive evidence regarding the efficacy of e-cigarettes as smoking cessation aids, Dufort and Owila (2014) cautioned against the use of this proposition without concrete empirical scientific evidence.

\section{Convenience}

Another dominant selling proposition used by e-cigarette retail websites is the convenience associated with using e-cigarettes relative to tobacco cigarettes. As indicated by website excerpts in Table 1, e-cigarettes are positioned as having a comparable advantage of being used in indoor environments and tobacco free zones. However, researchers such as Dufort and Owila (2014) caution against regarding e-cigarette use as convenient warning that, similar to conventional cigarettes, e-cigarettes also pose the danger of passive smoking to non-users. This view is supported by a chemical analysis of the e-cigarette vapour, which showed that it also contains toxicants and carcinogens found in tobacco cigarettes (Besaratinia \& Tommasi 2014; Goniewicz et al. 2013). When used indoors, Dufort and Owila (2014) found that vapour from e-cigarettes adversely affects air quality and exposes non-users to traces of metals such as lead and cadmium which have the potential of causing cardiac diseases. As a result of the threat posed by the vapour of e-cigarettes on air quality, Dufort and Owila (2014) warned that the convenience tag attached to e-cigarette use comes with a significant public health threat.

\section{Environment friendliness}

Environmental friendliness is one of the prevalent value propositions used to promote e-cigarettes on South Africa retail websites. As shown in Table 1, analysed websites use this proposition with e-cigarettes touted as a 'cleaner smoking alternative without the harmful effects of burning tobacco, smoke, tar and carbon monoxide'. Additionally, a number of websites were marketing what was dubbed the 'Green smoke variety pack'. Whilst there is consensus that conventional tobacco cigarettes are associated with veld fires and contamination of marine environments as a result of discarded tobacco butts (Chang 2014), e-cigarettes are not entirely environmentally friendly. For example, Krause and Townsend (2015) note that improper disposal of lithium batteries and cartridges with nicotine residues also pose significant threats to environmental sustainability. For this reason, Chang (2014) argues that unless proper education programmes on proper disposal of e-cigarette hardware are done, the claim that e-cigarettes are environmental friendly is misleading.

\section{Hedonic value}

The recreational attribute associated with e-cigarettes is one of the major value propositions used to market e-cigarettes. As indicated by websites excerpts in Table 1, e-cigarette flavours afford users a sensational smoking experience. It is apparent from website excerpts that flavours play a central role in attracting users and encouraging them to switch from conventional cigarettes. Additionally, website excerpts applaud the use of flavours for enhancing the social acceptance of users because of pleasant smell and taste. Researchers Vardavas, Filippidis and Agaku (2015) warned that the use of flavours has the potential to entice the youth to use e-cigarettes. This view is supported by the findings of a study conducted by Carpenter et al. (2005), which showed that youths are attracted to flavoured cigarettes. Additionally, the use of flavours in alcoholic beverages has been attributed to the high levels of alcohol abuse amongst the youth (Akre \& Suris 2015; Jones \& Reis 2011). There are also concerns related to the side effects associated with e-cigarette flavours. For instance, Farsalinos and Stimson (2014) report that e-cigarette flavours such as propionyl and caramel contain diacetyl and acetyl, which are associated with bronchiolitis obliterans.

\section{Cost-effectiveness}

Another recurring value proposition used to market e-cigarettes on South Africa retail websites is costeffectiveness. To entice first-time price-sensitive consumers, a discounted 'starter kit' is used. Additionally, promotions which include free delivery, contests and raffles amongst others are used to promote e-cigarette sales. However, researchers such as Farsalinos and Stimson (2014) cautioned against the cost-effectiveness tag attached to e-cigarettes. Pisinger and Dossing (2014) argued that the starter kit acts as bait to entice consumers to initiate using e-cigarettes and thereafter recruit them into premium e-cigarette brands that are expensive compared to conventional cigarettes. Moreover, Dutra and Glantz (2014) blamed the use of cheaper starter kits for acting as a gateway for non-smokers to initiate smoking. Other researchers such as Chen (2013) also alluded to the hidden costs associated with the use of e-cigarettes such as replacing e-cigarette hardware such as cartridges, nicotine refills and flavours.

\section{Safety}

Safety is another value proposition used to market e-cigarettes. As shown in Table 1, the websites analysed depict e-cigarettes as being safer than tobacco cigarettes. Although this claim was overwhelmingly used on e-cigarette retail websites, limitations were apparent in e-cigarettes labelling. For instance, nicotine content, manufacturing standards, quality controls and side effects of e-cigarettes were not fully disclosed. Lack of accurate disclosure of nicotine is a significant concern for public health practitioners because as noted by McQueen et al. (2011), it results in variations in the chemical composition of vapour inhaled and concentration of toxins. Because of an unregulated manufacturing process, Lu et al. (2015) raised a concern about the possibility of a mismatch between the actual e-cigarette nicotine with that declared on the label. Additionally, Kaisar et al. (2016) and Williams and Talbot (2011) note that lithium batteries used in e-cigarettes are 
susceptible to overheating, explosion and leakage, which heightens the risk profile of e-cigarettes. Moreover, Goniewicz et al. (2013) note that the risk profile of e-cigarettes is heightened by the variation in enforcement of quality controls in the manufacturing process.

\section{Implications of study findings}

The findings of this study have a number of implications for public health practitioners, e-cigarette marketers and consumers. Firstly, the proliferation of e-cigarette retail websites in South Africa calls for regulators to expedite the promulgation and enforcement of regulations necessary to monitor the production, marketing and use of e-cigarettes. In particular, quality controls and standardisation of the manufacturing process are important in order to address e-cigarette safety concerns. Such regulations also need to address inadequacies in e-cigarette labelling in order to minimise the use of unsubstantiated marketing claims. Secondly, there is an urgent need for public health practitioners to conduct a comprehensive, longitudinal conclusive scientific study in order to test the prevailing claim that e-cigarettes are safer than conventional cigarettes and that they are effective as smoking cessation aids. Thirdly, the findings of the study suggest the need for potential endusers of e-cigarettes to seek adequate information about the benefits and risks associated with e-cigarettes. Because the majority of young consumers in South Africa rely on online platforms to buy e-cigarettes, there is also a need to extend smoking-related regulations to also cover online platforms.

\section{Limitations}

This study has inherent limitations that are worth mentioning. The study was limited to retail websites dedicated to the marketing and sale of e-cigarettes. Other online platforms used to market e-cigarettes were not captured by the study. Future studies may focus on analysing marketing messages that are used to market e-cigarettes on other online platforms such as Facebook and YouTube. The e-cigarette market is rapidly changing; thus, the findings of this study may not be generalised to current websites' marketing messages. Owing to the content analysis nature of the study, it is not possible to predict the influence of e-cigarette marketing claims on consumer buyer behaviour. Future studies may seek to understand the influence of e-cigarette marketing claims on consumer attitudes and purchase intentions. Notwithstanding the aforementioned limitations, the findings of this study still provide valuable insights to consumers of e-cigarettes and policymakers.

\section{Conclusion}

The primary objective of this study was to analyse the selling propositions used to market e-cigarettes on South African retail websites. The main marketing claims utilised to market e-cigarettes include healthiness, cost-effectiveness, smoking cessation aid, environmental friendliness and hedonic value. It is important to state though that the risk profile of e-cigarettes is not comprehensively documented on South African retail websites. Also of greatest concern is that the majority of e-cigarette selling propositions on retail websites are based on unsubstantiated claims. This points to the urgent need for the promulgation and enforcement of e-cigarettes legislation in South Africa. Such legislation needs to be focused on regulating the manufacturing process, labelling, marketing, consumption and disposal of e-cigarettes. Aspects of the manufacturing process that require regulation include the chemical composition of flavours and nicotine content. Labelling regulations will play a central role in stamping out misleading marketing claims, especially inadequate disclosure of nicotine content and side effects of e-cigarettes. In order to address the uncertainties associated with the use of e-cigarettes, there is an urgent need for comprehensive scientific studies in order to understand the benefits and risks of e-cigarettes.

\section{Acknowledgements Competing interests}

The authors declare that they have no financial or personal relationships that may have inappropriately influenced them in writing this article.

\section{Authors' contributions}

A.M. conceptualised the study and compiled the literature relevant to the study. M.D. analysed the data and discussed the results.

\section{References}

Akre, C. \& Suris, J.C., 2015, 'E-cigarettes as a gateway to smoking: What do adolescents themselves think?' Journal of Adolescent Health 56(2), S31. https:// doi.org/10.1016/j.jadohealth.2014.10.062

Barbeau, A.M., Burda, J. \& Siegel, M., 2013, 'Perceived efficacy of e-cigarettes versus nicotine replacement therapy among successful e-cigarette users: A qualitative approach'. Addiction Science \& Clinical Practice 8(5), 2-7. https://doi org/10.1186/1940-0640-8-5

Besaratinia, A. \& Tommasi, S., 2014, 'Electronic cigarettes: The road ahead', Preventive Medicine 66, 65-67. https://doi.org/10.1016/j.ypmed.2014.06.014

Best, P., Taylor, B., Manktelow, R. \& McQuilkin, J., 2014, 'Systematically retrieving research in the digital age: Case study on the topic of social networking sites and young people's mental health', Journal of Information Science 40(3), 346-356.

Carpenter, C.M., Wayne, G.F., Pauly, J.L., Koh, H.K. \& Connolly, G.N., 2005, 'New cigarette brands with flavors that appeal to youth: Tobacco marketing cigarette brands with flavors that Health Affairs (Millwood) 24(6), 1601-1610. https://doi.org/10.1377/ hlthaff.24.6.1601

Caruana, D., 2016, Vaping industry thriving in South Africa, viewed 20 December 2017, from https://www.vapingpost.com/2016/07/15/vaping-industry-thrivingin-south-africa/

Chang, H., 2014, 'Research gaps related to the environmental impacts of electronic cigarettes', Tobacco Control 23(2), 54-58. https://doi.org/10.1136/ tobaccocontrol-2013-051480

Chen, I.L., 2013, 'FDA summary of adverse events on electronic cigarettes', Nicotine \& Tobacco Research 15, 615-616. https://doi.org/10.1093/ntr/nts145

Clarke, T.N. \& Lusher, J.M., 2017, 'Willingness to try electronic cigarettes among UK adolescents', Journal of Child \& Adolescent Substance Abuse 26(3), 175-182. https://doi.org/10.1080/1067828X.2016.1242098

Corbin, J. \& Strauss, A., 1990, 'Grounded theory research: Procedures, canons and evaluative criteria', Zeitschrift für Soziologie 19(6), 418-427. https://doi. org/10.1515/zfsoz-1990-0602

Dawkins, L., Turner, J., Roberts, A. \& Soar, K., 2013, “"Vaping” profiles and preferences: An online survey of electronic cigarette users', Addiction 108(6), 1115-1125. https://doi.org/10.1111/add.12150

Dinakar, C. \& O'Connor, G.T., 2016, 'The health effects of electronic cigarettes', New England Journal for Medicine 375, 1372-1381. https://doi.org/10.1056/ NEJMra1502466 
Dufort, A. \& Owila, A., 2014, 'E-cigarettes: The holy grail of smoking cessation or a new addiction?', University of Ottawa Journal of Medicine 4(2), 19-23. https:// doi.org/10.18192/uojm.v4i2.1158

Dutra, L.M. \& Glantz, S.A., 2014, 'Electronic cigarettes and conventional cigarette use among US adolescents: A cross-sectional study', JAMA Pediatrics 168(7), 610-617.

Etter, J.-F. \& Bullen, C., 2011, 'Electronic cigarette: Users profile, utilisation, satisfaction and perceived efficacy', Addiction 106, 2017-2028. https://doi.org/10.1111/ j.1360-0443.2011.03505.x

Etter, J.-F. \& Bullen, C., 2014, 'A longitudinal study of electronic cigarette users', Addictive Behaviour 39, 491-494. https://doi.org/10.1016/j.addbeh.2013.10.028

Farsalinos, K.E. \& Stimson, G.E., 2014, 'Is there any legal and scientific basis for classifying electronic cigarettes as medications?', International Journal of Drug Policy 25, 340-345. https://doi.org/10.1016/j.drugpo.2014.03.003

Fox, L., 2013, Countries where vaping is banned and why, viewed 22 June 2017, from https://ecigarettereviewed.com/countries-where-vaping-is-banned-and-why.

Goldsmith, C., 2016, The global e-cigarette market is set to be worth $\$ 32$ bn by 2021 , and the UK market will grow to $\$ 5.67 \mathrm{bn}$, viewed 20 October 2016, from http:// www.cityam.com/255646/global-e-cigarette-market-set-worth-32bn-2021-anduk-market

Goniewicz, M.L., Kuma, T., Gawron, M., Knysak, J. \& Kosmider, L., 2013, 'Nicotine levels in electronic cigarettes', Nicotine \& Tobacco Research 15(1), 158-166. https://doi. org $/ 10.1093 /$ ntr/nts103

Grana, R.A., 2013, 'Electronic cigarettes: Anew nicotine gateway?', Journal of Adolescen Health 52, 135-136. https://doi.org/10.1016/j.jadohealth.2012.11.007

Grana, R., Benowitz, N. \& Glantz, S.A., 2014, 'E-cigarettes: A scientific review', Circulation 129(19), 1972-1986. https://doi.org/10.1161/CIRCULATIONAHA.114.007667

Grana, R.A. \& Ling, P.M., 2014, 'Smoking revolution: A content analysis of electronic cigarette retail websites', American Journal of Preventive Medicine 46, 395-403. https://doi.org/10.1016/j.amepre.2013.12.010

Hajek, P., Etter, J.F., Benowitz, N., Eissenberg, T. \& McRobbie, H., 2014, 'Electronic cigarettes: Review of use, content, safety, effects on smokers and potential for harm and benefit', Addiction 109, 1801-1810. https://doi.org/10.1111/add.12659

Jansen, B.J. \& Pooch, U., 2001, 'A review of web searching studies and a framework for future research', Journal of the American Society for Information Science and Technology 52(3), 235-246.

Jones, S.C. \& Reis, S., 2011, 'Not just the taste: Why adolescents drink alcopops', Health Education 112(1), 61-74.

Kaisar, M.A., Prasad, S., Liles, T. \& Cucullo, L., 2016, 'A decade of e-cigarettes: Limited research and unresolved safety concerns', Toxicology 365, 67-75. https://doi. org/10.1016/j.tox.2016.07.020

Kim, H. \& Shin, H., 2013, 'Determination of tobacco-specific nitrosamines in replacement liquids of electronic cigarettes by liquid chromatography tandem mass spectrometry', Journal of Chromatography A 1291, 48-55. https://doi. org/10.1016/j.chroma.2013.03.035

King, B.A., Tynan, M.A., Dube, S.R. \& Arrazola, R., 2014, 'Flavored little cigars and flavored cigarette use among U.S. middle and high school students', Journal of Adolescent Health 54, 40-46. https://doi.org/10.1016/j.jadohealth.2013.07.033
Krause, M. \& Townsend, T.G., 2015, 'Hazardous waste status of discarded electronic cigarettes', Waste Management 39, 57-62. https://doi.org/10.1016/j. wasman.2015.02.005

Lu, W., Ferguson, S.G., Nichols, D., Patel, R. \& Jacobson, G.A., 2015, 'Determination of nicotine in cartridge-based electronic cigarettes', Analytical Letters 48(17), 2715-2722. https://doi.org/10.1080/00032719.2015.1048349

McQueen, A., Tower, S. \& Sumner, W., 2011, 'Interviews with "vapers": Implications for future research with electronic cigarettes', Nicotine Tobacco Research 13(9), 860-867. https://doi.org/10.1093/ntr/ntr088

Muposhi, A. \& Dhurup, M., 2016, 'Is vaping a panacea or peril: Consumer attitudes towards electronic cigarettes and relationship with quitting intention', African Journal for Physical Activity \& Health Sciences 21(4.1), 655-666.

Paek, H., Kim, S., Hove, T. \& Huh, J.Y., 2014, 'Reduced harm or another gateway to smoking? source, message, and information characteristics of e-cigarette videos on YouTube', Journal of Health Communication 19(5), 545-560. https://doi.org/1 $0.1080 / 10810730.2013 .821560$

Pardun, C.J., McKeever, R. \& Bedingfield, S., 2017, 'Smoke gets in their eyes? Third-person effects of electronic cigarette advertising', Journal of Promotion Management 23(5), 708-726. https://doi.org/10.1080/10496491. 2017.1297980

Pisinger, C. \& Døssing, M., 2014, 'A systematic review of health effects of electronic cigarettes', Preventive Medicine 69, 248-260. https://doi.org/10.1016/j. ypmed.2014.10.009

Pokhrel, P., Herzog, T.A., Muranaka, N. \& Fagan, P., 2015, 'Young adult e-cigarette users' reasons for liking and not liking e-cigarettes: A qualitative study', Psychology \& Health 301(2), 1450-1469. https://doi.org/10.1080/08870446. 2015.1061129

Van Rensburg, D. \& Moodley, N., 2017, Smoking industry heats up, viewed 02 February 2017, from https://www.fin24.com/Economy/the-return-of-safersmokes-20170120

Vardavas, C.I., Filippidis, F.T. \& Agaku, I.T., 2015, 'Determinants and prevalence of e-cigarette use throughout the European Union: A secondary analysis of 26 566 youth and adults from 27 countries', Tobacco Control 24(5), 442-448.

Visagie, J., 2017, The huff and puff surrounding e-cigarette regulation in South Africa, viewed 20 June 2017, from http://www.bizcommunity.com/ Article/196/716/161768.html

Wasowicz, A., Feleszko, W. \& Goniewicz, M.L., 2015, 'E-cigarette use among children and young people: The need for regulation', Expert Review of Respiratory Medicine 9, 507-509. https://doi.org/10.1586/17476348.2015.1077120

West, R. \& Brown, J., 2014, 'Electronic cigarettes: Fact and faction', British Journal of General Practice 64, 442-443. https://doi.org/10.3399/bjgp14X681253

Williams, M. \& Talbot, M.P., 2011, 'Variability among electronic cigarettes in the pressure drop, airflow rate, and aerosol production', Nicotine Tobacco Research 13, 1276-1283. https://doi.org/10.1093/ntr/ntr164

Zhu, S.H., Sun, J.Y., Bonnevie, E., Cummins, S.E., Gamst, A., Yin, L. et al., 2014 'Four hundred and sixty brands of e-cigarettes and counting: Implications for product regulation', Tobacco Control 23(3), 3-9. https://doi.org/10.1136/ tobaccocontrol-2014-051670 